\title{
RISK ANALYSIS AND ENVIRONMENTAL HAZARD MANAGEMENT
}

\author{
K. Veerabhadram ${ }^{1}$, K. Satti Babu ${ }^{2}$ \\ ${ }^{1}$ Professor in Civil Engineering, GITAM Institute of Technology, GU, Visakhapatnam \\ ${ }^{2}$ Ph.D. Scholar in Civil Engineering, GIT, GU
}

\begin{abstract}
Risk is defined as 'the possibility of loss or injury. Hazard is defined as the source of risk Toxicity is describes as capability to produce an adverse effect on living organisms. Risk assessment refers to the factual bases for determining exposure, adverse effects (i.e., toxicity) and dose-response relationships and for predicting their nature and magnitude in humans.

Any organization has a legal and moral obligation to safeguard the health and welfare of the general public and to ensure environmental safety. All manufacturing process are to some extent. Hazardous but in processes involving hazardous substances such as petroleum, natural gas and other chemicals. There are additional special hazards associated with the properties of the substances and process conditions. The designer must be aware of these hazards, and ensure, through the application of Sound Engineering practice, that the risks are reduced to acceptable levels.
\end{abstract}

A qualitative approach to the risk analysis and Environmental Hazard Management is presented in this paper along with a hypothetical Gas Collecting Station and a Dispersion Model.

\section{INTRODUCTION}

It has long since been known that industrial establishments are the major sources of environmental pollution. The inherent operational inadequacies of industries, chemical processing plants, oil refineries, atomic power plants are found to be the major causes of environmental hazard. Although a Civil Engineer is well acquainted with the techniques involved in Environmental impact Assessment, due to the various developments that have taken place in the field of Environmental Science, the Civil Engineer needs to be more innovative and enterprising.

The Civil Engineer has to possess certain knowledge of the more complicated techniques used to evaluate the risk to the environment and to manage the hazards and accidents arising from the risk.

Therefore, a qualitative and quantitative approach to the risk analysis and Environmental Hazard Management is presented in this paper along with a case study of a hypothetical Gas Collecting Station

Steps involved in identification and assessment of hazards: The various steps in identification and assessment of hazards are

i) Hazard identification HAZID - Failure Mode Analysis Accident Scenario.

ii) Hazard operability study (HAZOP).

iii) Hazard analysis (HAZAN).

Hazard Identification (HAZID): This consists of recognizing the various hazards that could occur, their mode or occurrence and the areas in which a hazard may occur and its area or influence.
Hazard Operability (HAZOP) Study: This examines the cause - effect relationship for various process units under operation i.e., the various consequences that are brought about by certain deviation in process parameters such as pressure, temperature etc.

Hazard Analysis (HAZAN): This involves the quantification of hazard and the probability of occurrence of hazard after a hazard is identified and its cause effect relationship established using Reliability Techniques and Fault Tree Analysis (FTA).

\section{HAZARD IDENTIFICATION (HAZID)}

Hazard identification is carried out by studying the process involved in the industrial activity, the piping and instrumentation and control systems. This involves the preparation of layout maps of the process units and the study of the process taking place and thereby reducing the risk factors associated with the process. This gives a qualitative idea of the various hazards that may occur in the process area.

\section{Fire and Explosion Index}

The safety and loss prevention guide developed by the Dow Chemical Company, and published by the American Institute of Chemical Engineer, Dow (1973), gives a method for evaluating the potential hazards of a process and assessing the safety and loss prevention measures needed. A numerical "Fire and Explosion Index" is calculated, based on the nature of the process and the properties of the materials. The larger the value of the index, the more hazardous is the process. When used to evaluate the design of a new plant, the index is normally calculated after the piping and Instrumentation diagrams and equipment layout have been prepared, and is used a a guide to the selection 
and design of the preventive and protection equipment needed for safe plant operation. It may be calculated at an early stage in the process design, after the preliminary flowsheets have been prepared, and will indicate whether alternative, less hazardous, processes should be considered.

\section{Dispersion studies}

Pollutants emitted into the atmosphere are mixed thoroughly with the surrounding air and diluted by atmospheric dispersion. This dispersion is primarily due to turbulent diffusion and bulk air flow.

\section{The Gaussian plume Model}

The present tendency is to interpret dispersion data in terms of the Gaussian model. The standard deviations are related to the eddy diffusivities through the equations, functions of downwind distance $\mathrm{x}$ from the source as well as the atmospheric stability conditions.

\section{Gas Collection Module}

The following operating stages are involved in the Gas Collection Module:

Manifolding of gas and liquid: The well fluid lines from the wells are combined into the production and Test Separators respectively. The manifold is provided with pressure indicators, shut down valves and pressure safety valves on production and Test Headers respectively.

Liquid separation in Production and Test Separators: The natural gas and the liquid are separated in vessels called separators by cyclonic recycling and gravity separation. The production and Test Separators are provided with pressure safety valves respectively. The liquid from the separators is taken to the Condensate Recovery System.

Condensate Recovery: The liquid hydrocarbon condensate along with water, if any, is taken to the condensate K.O. Drum whichis designed as storage -cum-separator vessel to carry out 3-phase separation of gas, oil and water.

Filtration: The gas after pressure reduction is fed to the final polishing filter which is fitted with filter elements which are capable of removing $99.9 \%$ of solid/ liquid particles of size above 0.5 micron.

Flare System: All the safety valve discharges are connected to a flare header which joins to the Flare K.O. Drum which separates any flared liquid which would otherwise create fire spitting from the stack. A flare stack is located at a distance of $90 \mathrm{~m}$ away from the K.O. Drum. The flare system is designed for automatic and unmanned operation.

\section{TYPES OF ACCIDENTS}

Based on the information so far gathered from the Fire and Explosion Index Approach and Process and Instrumentation Analysis, the following typical accident cases are indentified.
* $\quad$ Failure / rupture of safety valve

* $\quad$ Failure / rupture of tanks / equipment

The various possible scenarios that may occur after the release due to the failures indentified above are represented in the form of a flow chart given overleaf.

\section{HAZARDS}

The main hazards likely to be caused due to any failure/ rupture in equipment are generally classified as under :

(i) Fire - This may either cause formation of a pressure wave or Heat Radiation

(ii) Toxicity - The release of hazardous material in the form of liquid or vapour may lead to high toxicity

(iii) Explosion - The dispersion of liquid or vapour which on subsequent ingnition may result in a vapour cloud explosion which leads to heat radiation and pressure wave formation.

\section{HAZARD ANALYSIS}

An operability study will identify potential hazards, but gives not guidance on the likelihood of an accident occurring, or the loss suffered; this is left to the intuition of the team members. Incidents usually occur through the coincident failure of two or more items; failure of equipment, control systems and instruments, and misoperation. The sequence of events that leads to hazardous incident can be shown as a fault tree.

\section{HAZARD MANAGEMENT}

So far the hazards have been indentified, their operability has been discussed and they have been analyzed which collectively have given us a qualitative and quantitative perception of the risk. Thus, a cause effect relationship has been established.

The next step would naturally be the prevention Control and Relief operations pertaining to the environmental hazard. Such a treatment can be classified under the heading Hazard Management.

The Hazard Management consists in the following steps:

\section{Basic Preventive and Protective Measures}

The basic preventive and protective measures that should be adopted in all industrial processes are given as below:

(i) Adequate and secure water supplies for fire fighting

(ii) Correct structural design of vessels, piping and steel work

(iii) Pressure relief devices

(iv) Corrosion - resistant materials, and/or adequate corrosion allowances

(v) Segregation of reactive materials

(vi) Earthing of electrical equipment

(vii) Safe location of auxiliary electrical equipment, transformers, switch gear

(viii) Provision of back-up utility supplies and services

(ix) Compliance with national codes and standards

(x) Fail - safe instrumentation 
(xi) Provision for access of emergency vehicles and the evacuation of personnel.

(xii) Adequate drainage for spills and fire fighting water

(xiii) Insulation of hot surfaces

(xiv) No glass equipment should be used for flammable hazardous materials unless no suitable alternative is available.

(xv) Adequate separation of hazardous equipment

(xvi) Protection of pipe racks and cable trays from fire

(xvii) Provision of block valves on lines to main processing areas

(xviii) Protection of fired equipment ( heaters , furnaces against accidental explosion and fire

(xix) Safe design and location of control rooms

(xx) Maintenance of proper separation distances between process units.

\section{Training of personnel and public Awareness}

Training programmes in safety and accident prevention should be organized for all levels of employees with a view to familiarizing them with general safety rules and safety procedures to be followed in various operational activities and to update their knowledge in safety, accident prevention, industrial hygiene, emergency procedures, first aid and use of various safety appliances.

Public Awareness programmes necessary for taking timely action by the neighboring population/ inhabitants in the event of major emergencies should be made in coordination with civic authorities and local area representatives to prevent heavy casualties.

First Aid Training which includes first aid techniques and procedures for artificial respiration should be imparted to all the employees as well as public with the help of qualifying medical and paramedical staff.

\section{Control Measures}

$>$ Containment of toxic materials by sound design of equipment and piping.

$>$ Disposal of toxic material by providing effective vent stacks to disperse the material.

$>$ vented from pressure relief devices and by the use of vent scrubbers .

$>$ Ventilation should be provided adequately by the use of open structures and ventilation systems.

$>$ There should be proper escape routes, emergency and rescue equipment, safety showers and eyebaths provided near the processing plant.

\section{Fire and Explosion protection}

The fire and explosion protection has to be provided in the following forms

(i) Provision of flame traps which contain and arrest the propagation of flame

(ii) Provision of water tanks, hose pipes, sprinkler system and fire extinguishers for dousing the fire.

(iii) Adequate fire proofing should be provided (iv) Special instrumentation in the form of temperature controls, pressure controls and flow controls

(v) Internal explosion protection along with dump, blow down spill control

(vi) Remote operation and availability of combustible gas monitors

(vii) Proper civil engineering design in the form of Dykeing, blast and barrier valves.

\section{Relief Operations}

The relief operations that have to be carried out for the mitigation of major accidents are as follows:

Prompt intimation of the accident to the nearest fire station

Following the emergency plan containing system of organization used to fight the emergency, the alarm and the communication routes, guidelines for fighting the emergency, information about hazardous materials and possible accident

(iii) Following the contingency plan for the mitigation of accident in case of fire, explosion, gas leakage and hazardous material spill.

\section{CONCLUSION}

Environmental Engineering has fast emerged as a separate and self-sustaining discipline over the recent years. The more subject specific topics like Risk Analysis and Industrial Safety which have hitherto been dealt with under chemical and Industrial Safety have come under the purview of Environmental Engineering. Accidents of catastrophic degree such as the Chernobyl Nuclear disaster (erstwhile USSR), the Bhopal Gas Tragedy and the more oil spills that have occurred during the Gulf War have made both the governments and the public more aware of the detrimental effects of the environmental hazards on life and property.

In this context, the Risk Analysis and Environmental Hazard Management has become an integral part of the multifaceted discipline of Environmental Engineering. Thus, the foregoing discussion serves as an effective tool for the preservation and protection of environment from various hazards.

\section{REFERENCES}

1. Irving.N. Sax. Dangerous properties of Hazardous Materials.

2. A. Guide to Hazard and operability studies ( Chemical Industries Association, London)

3. King.R. and Magid. J. ( 1979 ) Industrial Hazard and Safety Handbook ( Newnes - Butterworths )

4. Kletz. T.A. (1971) Inst. Chem. Eng. Sym. Ser. No. 3475 . Hazard analysis - a quantitative approach to safety.

5. Lawley . H.G. (1974) Loss prevention No. 8 ( AIchE ) 105 - Operability studies and Hazard analysis. 